\title{
Association of serum ferritin levels with smoking and lung function in the Korean adult population: analysis of the fourth and fifth Korean National Health and Nutrition Examination Survey
}

\author{
This article was published in the following Dove Press journal: \\ International Journal of COPD \\ 29 November 2016 \\ Number of times this article has been viewed
}

\author{
Chan Ho Lee \\ Eun Kyung Goag \\ Su Hwan Lee \\ Kyung Soo Chung \\ Ji Ye Jung \\ Moo Suk Park \\ Young Sam Kim \\ Se Kyu Kim \\ Joon Chang \\ Joo Han Song \\ Division of Pulmonology and Critical \\ Care Medicine, Department of \\ Internal Medicine, Institute of Chest \\ Disease, Severance Hospital, Yonsei \\ University College of Medicine, Seoul, \\ Republic of Korea
}

\begin{abstract}
Background: Iron-catalyzed oxidative stress contributes to lung injury after exposure to various toxins, including cigarette smoke. An oxidant/antioxidant imbalance is considered to play a critical role in the pathogenesis of COPD. Ferritin is a key protein in iron homeostasis, and its capacity to oxidize and sequester the metal preventing iron prooxidant activity implicates its possible role in the alteration of antioxidant imbalance. We investigated the relationship among cigarette smoking, lung function, and serum ferritin concentration in a large cohort representative of the Korean adult population.
\end{abstract}

Materials and methods: Among 50,405 participants of the Korean National Health and Nutrition Examination Survey from 2010 to 2014, 15,239 adult subjects older than 40 years with serum ferritin levels and spirometric data were selected for this study.

Results: The mean age was 56.5 years for men (43\%) and 56.9 years for women (57\%). The prevalence of airway obstruction was $13.4 \%$, which was significantly higher in men than in women, and increased in former or current smokers. The median levels of serum ferritin were highest in the airway obstruction group, followed by the restrictive pattern group, and lowest in the normal lung function group. The median ferritin levels were increased by smoking status and amounts in each spirometric subgroup. In multivariable regression analysis, serum ferritin was positively associated with forced expiratory volume in 1 second and forced expiratory volume in 1 second/forced vital capacity, whereas the smoking amount was negatively associated with the adjustment with age, sex, height, and weight.

Conclusion: Serum ferritin levels were increased in former or current smokers and were increased with smoking amount in all subgroups of participants categorized according to spirometric results. The result was also evident in the subgroups divided by obstructive severity. While smoking amount was inversely related to lung function, higher levels of serum ferritin were associated with enhanced spirometric results in a representative sample of the general Korean adult population. Future prospective studies will be needed to clarify the causality between serum ferritin and lung functions and their role in COPD morbidity.

Keywords: airway obstruction, ferritin, smoking

\section{Introduction}

Although iron is an essential nutrient widely used for normal cell function, elevated iron concentrations in the lungs are associated with an increased risk of pulmonary injury. Iron-catalyzed oxidative stress contributes to lung injury after exposure to various toxins, including cigarette smoke. Smoking has been suggested to increase 
the concentration of iron in the alveolar macrophages and bronchoalveolar lavage fluid to very high levels and to alter iron homeostasis, both in the lung and systemically. ${ }^{1-4}$

COPD is one of the most common lung diseases, affecting $\sim 10 \%$ of the population older than 40 years worldwide, ${ }^{5}$ while a recent Korean nationwide surveillance indicated its higher prevalence in the Korean population. ${ }^{6}$ An imbalance between oxidants and antioxidants is considered to play a critical role in COPD pathogenesis, ${ }^{7,8}$ while cigarette smoking is a key risk factor for COPD development, and most COPD patients are current or former smokers. ${ }^{9}$

Ferritin, a ubiquitous intracellular protein, is one of the key proteins that regulates body iron homeostasis and is a marker of the iron store. ${ }^{10}$ This study investigated the relationship among cigarette smoking, lung function, and serum ferritin concentration, using data collected from subjects participating in the Korean National Health and Nutrition Examination Survey (KNHANES) from 2010 to 2014.

\section{Materials and methods}

\section{Study population}

The KNHANES is a cross-sectional survey of health-related behaviors, health conditions, and the nutritional state of the Korean population (adults and children) and yields basic statistics for establishing health policies. For this study, data from the 2010-2014 surveys (KNHANES IV-V) were used, which employed a stratified, multiple-stage, clusteredprobability design to select a representative sample of noninstitutionalized civilians from among the Korean population. These data comprised information on age, ethnicity, sex, height, weight, smoking status, residency, household income, past history of pulmonary tuberculosis and asthma, and prebronchodilator spirometry values.

The study protocol was approved by the institutional review board of Yonsei University Health Service, Severance Hospital (approval number: 4-2006-0101), and was conducted in accordance with the Declaration of Helsinki. All the participants in the survey provided written informed consent.

Among the KNHANES IV-V participants $(\mathrm{N}=50,405)$, all individuals older than 40 years who were examined for serum ferritin levels and spirometric data were included in this study.

\section{Spirometric tests}

After explaining the procedure of spirometry to participants in detail, spirometry measurements were conducted by four technicians, each of whom underwent two education sessions on pulmonary function testing and quality control, and the principal investigator determined whether they met the criteria for acceptability and reproducibility. Spirometry (Vmax 2130 Dry Rolling-seal Spirometer; SensorMedics, Yorba Linda, CA, USA) was performed according to the guidelines of the American Thoracic Society/European Respiratory Society for standardizing the pulmonary function tests. ${ }^{11}$ Data that produced two acceptable spirometry curves, ie, showing the start of the test and expiration for $\geq 6$ seconds, with the greatest difference between the two measurements of forced expiratory volume in 1 second $\left(\mathrm{FEV}_{1}\right)$ and forced vital capacity (FVC) $<150 \mathrm{~mL}$, were included in the analysis.

"Airway obstruction" was defined using the ratio of $\mathrm{FEV}_{1}$ to $\mathrm{FVC}\left(\mathrm{FEV}_{1} / \mathrm{FVC}\right)<70 \%$ as a fixed cut-off point according to the guidelines set by the Global Initiative for Chronic Obstructive Lung Disease (GOLD). ${ }^{12}$ The severity of airway obstruction was classified as "mild" $\left(\mathrm{FEV}_{1} \geq 80 \%\right.$ predicted, GOLD stage I), "moderate" $\left(50 \% \leq \mathrm{FEV}_{1}<80 \%\right.$ predicted, GOLD stage II), and "severe" $\left(\mathrm{FEV}_{1}<50 \%\right.$ predicted, GOLD stages III-IV). In addition, "normal lung function" was defined as $\mathrm{FEV}_{1} / \mathrm{FVC} \geq 70 \%$ and $\mathrm{FVC} \geq 80 \%$ predicted. A "restrictive spirometric pattern" was defined as $\mathrm{FEV}_{1} / \mathrm{FVC} \geq 70 \%$ and $\mathrm{FVC}<80 \%$ predicted.

\section{Serum ferritin level measurement}

Serum ferritin was measured by immunoradiometric assay using a 1470 Wizard Gamma Counter (PerkinElmer Inc., Waltham, MA, USA).

\section{Statistical analyses}

Data were analyzed using SAS v9.2 (SAS Institute Inc., Cary, NC, USA). Baseline characteristics were summarized using frequencies and percentages to describe categorical variables and compared using the chi-square test. Serum ferritin levels were compared using analysis of variance and are presented as the median and interquartile range (IQR). Serum ferritin level was logarithmically transformed because of the skewed nature of its distribution. Multivariable linear regression analysis using a stepwise backward technique was performed to assess the correlation among lung function, cigarette smoking, and serum ferritin concentration in a multivariable model adjusted for age, sex, height, and weight. Statistical significance for all analyses was accepted at a level of $P<0.05$.

\section{Results}

\section{Population characteristics according to spirometric patterns}

The baseline characteristics of the 15,239 study subjects are summarized in Table 1. The mean age was 56.5 years for 
Table I Characteristics of study population according to spirometric results

\begin{tabular}{|c|c|c|c|c|c|c|c|c|c|}
\hline \multirow[t]{2}{*}{ Characteristics } & \multirow[t]{2}{*}{ Total } & \multicolumn{4}{|c|}{ Spirometric results } & \multicolumn{4}{|c|}{ Obstructive severity } \\
\hline & & Normal & Restrictive & Obstructive & $P$-value & Mild & Moderate & Severe & $P$-value \\
\hline Number (\%) & 15,239 & I I,477 (75.3) & I,727 (II.3) & $2,035(13.4)$ & & $907(6.0)$ & $\mathrm{I}, 023(6.7)$ & $105(0.7)$ & \\
\hline \multicolumn{10}{|l|}{ Age group (years) } \\
\hline $40-49$ & 4,610 & $4,106(89.1)$ & $339(7.4)$ & $165(3.6)$ & $<0.001$ & $55(33.3)$ & $108(65.5)$ & $2(1.2)$ & 0.323 \\
\hline $50-59$ & 4,626 & $3,736(80.8)$ & $464(10.0)$ & $426(9.2)$ & & I 75 (4I.I) & $225(52.8)$ & $26(6.1)$ & \\
\hline $60-69$ & 3,728 & $2,458(65.9)$ & $540(14.5)$ & $730(19.6)$ & & $307(42.1)$ & $390(53.4)$ & $33(4.5)$ & \\
\hline$\geq 70$ & 2,275 & $\mathrm{I}, \mathrm{I} 77(5 \mathrm{I} .7)$ & $384(16.9)$ & $714(31.4)$ & & $370(51.8)$ & $300(42.0)$ & $44(6.2)$ & \\
\hline \multicolumn{10}{|l|}{ Sex } \\
\hline Men & 6,613 & $4,325(65.4)$ & $815(12.3)$ & $\mathrm{I}, 473(22.3)$ & $<0.001$ & $664(45.1)$ & $728(49.4)$ & $8 \mathrm{I}(5.5)$ & $<0.001$ \\
\hline Women & 8,626 & $7,152(82.9)$ & $912(10.6)$ & $562(6.5)$ & & $243(43.2)$ & $295(52.5)$ & $24(4.3)$ & \\
\hline \multicolumn{10}{|l|}{ Smoking status } \\
\hline Never smoker & 9,223 & $7,569(82.1)$ & I,0I5 (II.0) & $639(6.9)$ & $<0.00$ I & $268(41.9)$ & $347(54.3)$ & $24(3.8)$ & 0.029 \\
\hline Exsmoker & 3,180 & $2,026(63.7)$ & $395(12.4)$ & $759(23.9)$ & & $358(47.2)$ & $353(46.5)$ & $48(6.3)$ & \\
\hline Current smoker & 2,836 & $\mathrm{I}, 882(66.4)$ & $317(11.2)$ & $637(22.5)$ & & $28 I(44 . I)$ & $323(50.7)$ & $33(5.2)$ & \\
\hline \multicolumn{10}{|c|}{ Smoking amount (pack-year) } \\
\hline 0 & 9,225 & 7,57I (82.1) & I,0I5 (II.0) & $639(6.9)$ & $<0.001$ & $268(41.9)$ & $347(54.3)$ & $24(3.8)$ & 0.002 \\
\hline $0-19.9$ & 2,702 & $\mathrm{I}, 95 \mathrm{I}(72.2)$ & $297(11.0)$ & $454(16.8)$ & & $234(51.5)$ & $195(43.0)$ & $25(5.5)$ & \\
\hline$>20$ & 3,312 & $1,955(59.0)$ & $415(12.5)$ & $942(28.4)$ & & $405(43.0)$ & $48 I(5 I . I)$ & $56(5.9)$ & \\
\hline \multicolumn{10}{|l|}{ Anemia } \\
\hline Yes & 740 & $990(8.6)$ & I75 (I0.I) & $155(7.6)$ & 0.023 & $73(8.1)$ & $73(7.1)$ & $9(8.6)$ & 0.700 \\
\hline No & 14,499 & $10,487(9 \mid .4)$ & I,552 (89.9) & $\mathrm{I}, 880(92.4)$ & & 834 (92.9) & $950(92.9)$ & $96(91.4)$ & \\
\hline
\end{tabular}

Notes: Data are presented as numbers (percentages) for categorical variables. Anemia was defined as $<13 \mathrm{~g} / \mathrm{dL}$ hemoglobin for men and $<12 \mathrm{~g} / \mathrm{dL}$ hemoglobin for women. $P$-value was calculated using one-way analysis of variance.

men and 56.9 years for women. The study population was grouped into three subgroups according to the spirometric results: normal pattern $(n=11,477)$, restrictive pattern $(\mathrm{n}=1,727)$, and obstructive pattern (airway obstruction; $\mathrm{n}=2,035)$. Of all 15,239 study individuals, the prevalence of airway obstruction was $13.4 \%$, which was significantly higher in men $(22.3 \%)$ than in women $(6.5 \%)$, while a normal spirometric pattern was more common in women $(82.9 \%)$ than in men (65.4\%). The prevalence of airway obstruction was increased in ever smokers (former or current) and with the amount smoked. Both restrictive and obstructive patterns were more common among the older age groups. Anemia was more frequent in the restrictive subgroup (10.1\%) than in those with normal lung function $(8.6 \%)$ or with airway obstruction (7.6\%). In the obstructive subgroup $(n=2,035)$, the presence of anemia did not differ significantly according to the severity of obstruction (Table 1). Additionally, the prevalence of airway obstruction was higher in subjects living in urban areas $(16.8 \%)$ than in those living in a rural area $(12.2 \% ; P<0.001)$ and was more frequently observed with a higher household income (first quartile: $21.9 \%$, second quartile: $14 \%$, third quartile: $10.6 \%$, and fourth quartile: $8.8 \% ; P<0.001)$. The prevalence of airway obstruction was $28.8 \%$ in individuals with a history of pulmonary tuberculosis $(n=1,040)$ and $12.2 \%$ in those without such a history (n=14,199; $P<0.001)$. Furthermore, airway obstruction was more prevalent in subjects with asthma $(n=740)$ than in those without this condition $(\mathrm{n}=14,499 ; 36.5 \%$ vs $12.2 \%$; $P<0.001)$.

\section{Serum ferritin level of the study populations}

Table 2 shows the median levels of serum ferritin in the three groups with normal lung function, a restrictive spirometric pattern, and airway obstruction, according to age groups, sex, smoking status, and smoking amount. The airway obstruction group had a higher serum ferritin level in all age groups. The median levels of serum ferritin were highest in the airway obstruction group (83.9 $\mu \mathrm{g} / \mathrm{L})$ (IQR: 50.3-138.9), followed by the restrictive pattern group $(74.6 \mu \mathrm{g} / \mathrm{L})(\mathrm{IQR}$ : 42.6-128.3), and lowest in the normal lung function group (62.3 $\mu \mathrm{g} / \mathrm{L})$ (IQR: 33.9-104.8). Ex- or current smokers had higher serum ferritin levels than never smokers in all three groups categorized by spirometric pattern.

Although women had lower levels of serum ferritin than men in all three spirometric groups, the level of serum ferritin was significantly lower in women with a normal spirometric pattern than in women with an obstructive pattern $(45.3 \mu \mathrm{g} / \mathrm{L}$ vs $55.9 \mu \mathrm{g} / \mathrm{L})$. Conversely, among the women with airway obstruction ( $n=562)$, the serum ferritin showed a trend toward a lower level in those with severe obstruction $(38.3 \mu \mathrm{g} / \mathrm{L}$ vs $56.6 \mu \mathrm{g} / \mathrm{L})$ than those with mild obstruction $(P=0.404)$. For men, the level of serum ferritin was higher in those with a normal spirometric pattern than in those with airway 


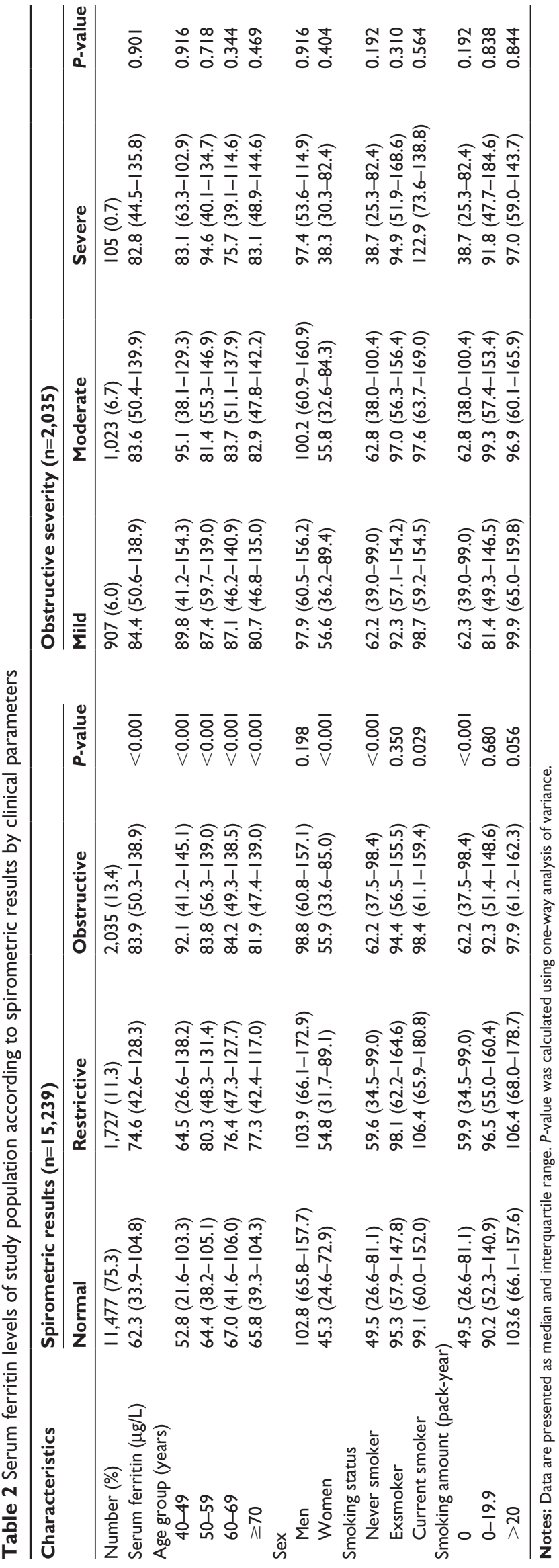

obstruction $(102.8 \mu \mathrm{g} / \mathrm{L}$ vs $98.8 \mu \mathrm{g} / \mathrm{L} ; P=0.198)$. Additionally, the serum ferritin level was higher in men than in women in all subgroups determined by smoking status. Because of the skewed nature of the distribution, serum ferritin levels were also logarithmically transformed, and the median levels of the log-transformed serum ferritin (SD) were 1.91 (0.37), 1.84 (0.41), and 1.74 (0.43) in obstructive, restrictive, and normal spirometric patterns, respectively $(P<0.001)$. In the male population, the median level of the log-transformed serum ferritin was highest in current smokers, while it was highest in exsmokers in women (Table 2).

\section{Predictors of decreased lung function}

We performed multivariable linear regression analyses to determine the relationships among spirometric results $\left(\mathrm{FEV}_{1}\right.$ and $\mathrm{FEV}_{1} / \mathrm{FVC}$ ), serum ferritin, and smoking amounts. After adjustment for age, sex, height, and weight, serum ferritin levels were positively associated with $\mathrm{FEV}_{1}$ and $\mathrm{FEV}_{1} / \mathrm{FVC}$, whereas the smoking amount was negatively associated with these values in our study population (Table 3 ).

\section{Discussion}

In this cross-sectional study, we analyzed the associations among serum ferritin levels, cigarette smoking, and lung function in a large cohort derived from the Korean population older than 40 years. Increased amounts of cigarette smoking were related to higher serum ferritin levels, while lower serum ferritin levels were significantly related to decrease in $\mathrm{FEV}_{1}$ and $\mathrm{FEV}_{1} / \mathrm{FVC}$ values. The positive correlation among log-transformed ferritin levels, smoking amounts, and lung function assessed by spirometric data remained significant after adjustment for independent covariates, such as age, sex, height, and weight. Collectively, these findings suggest that the iron store may affect pulmonary physiology and, possibly, the risk of airway obstruction, while smoking may alter iron homeostasis.

Iron is an essential micronutrient that is used in almost every aspect of normal cell function. However, its ability to catalyze the formation of reactive oxygen species can also be a health threat, which can lead to oxidative stress and damage cellular membranes. ${ }^{13}$ Cigarette smoke contains numerous oxidants and prooxidants capable of producing free radicals and enhancing oxidative stress. ${ }^{14}$ Previous studies have suggested the influence of cigarette smoking on iron status by demonstrating cigarette smoke-induced release of iron from ferritin by aqueous extracts of cigarette smoke ${ }^{15}$ and that such iron mobilization acts as a specific prooxidant mechanism during smoking. ${ }^{16}$ In addition to other studies showing the increased 
Table 3 Multivariable linear regression analysis for relationship between serum ferritin levels and FEV, and FEV,/FVC

\begin{tabular}{|c|c|c|c|c|c|c|c|c|}
\hline \multirow[t]{2}{*}{ Variables } & \multicolumn{4}{|c|}{ FEV $(\%)$ predicted } & \multicolumn{4}{|c|}{ FEV,/FVC (\%) predicted } \\
\hline & $\beta$ & SE & $P$-value & $R^{2}$ (adjusted) & $\beta$ & SE & $P$-value & $R^{2}$ (adjusted) \\
\hline Serum ferritin (log-transformed) & 0.02269 & 0.00840 & 0.007 & 0.6819 & 0.00294 & $0.0014 I$ & 0.037 & 0.2801 \\
\hline Age (years) & -0.02539 & 0.00032 & $<0.001$ & & -0.00289 & 0.00005 & $<0.001$ & \\
\hline Sex (men) & -0.41599 & 0.01116 & $<0.001$ & & 0.01668 & 0.00187 & $<0.001$ & \\
\hline Smoking amount (pack-year) & -0.00415 & 0.00023 & $<0.001$ & & -0.00084 & 0.00004 & $<0.001$ & \\
\hline Height (cm) & 0.03225 & 0.00065 & $<0.001$ & & -0.00184 & 0.00011 & $<0.001$ & \\
\hline Weight (kg) & 0.00130 & 0.0004 I & 0.001 & & 0.00104 & 0.00007 & $<0.001$ & \\
\hline
\end{tabular}

Note: Serum ferritin level was logarithmically transformed because of the skewed nature of its distribution. Abbreviations: FEV , forced expiratory volume in I second; FVC, forced vital capacity; SE, standard error

lavage iron stores in smokers, ${ }^{2,17}$ Ghio et al ${ }^{4}$ in their animal experiments suggested an alteration in iron homeostasis from cigarette smoke exposure. More specifically, they have shown that such exposure leads to iron accumulation that is dependent on particulates in the smoke and that this change affects oxidative stress, which is responsible for tissue inflammation after smoking. They suggested that the complexation of host iron by particulate matter in the tar phase of cigarette smoke will alter iron homeostasis, both in the lung and systemically. ${ }^{4}$

In order to regulate iron-catalyzed oxidative stress, lung epithelial cells can rapidly increase the expression of ferritin protein. ${ }^{1}$ Ferritin restricts the capacity of iron to generate reactive oxygen species and free radicals via iron sequestration and, thus, serves as an antioxidant protein. ${ }^{18}$ Using human lavage samples, Ghio et $\mathrm{al}^{4}$ demonstrated significantly increased ferritin concentrations in healthy smokers and smokers with COPD when compared with healthy nonsmokers. Using National Health and Examination Survey III data from $>7,000$ subjects, they also demonstrated significant increases in serum iron and ferritin levels and transferrin saturation among smokers relative to nonsmokers. A prior study by Touitou et a ${ }^{19}$ reported significantly higher levels of plasma ferritin in smokers than in nonsmokers in an elderly population. Our study extends these observations in a larger cohort of $>15,000$ subjects, representative of the general Korean population.

In our results, the levels of serum ferritin were highest among subjects with an obstructive pattern, grouped according to spirometric data, and defined as $\mathrm{FEV}_{1} / \mathrm{FVC}<70 \%$. This indicates the impact of smoking on serum ferritin levels, considering that $\sim 70 \%$ of those with an obstructive pattern were former or current smokers. Alternatively, in the subgroup analysis of only subjects with an obstructive pattern, the levels of serum ferritin were decreased in the subgroups with severe obstruction as defined by sex and smoking. Although the role of iron in COPD has not been clarified, our results of a positive correlation between serum ferritin levels and lung function parallel the findings of studies that explored iron status in other respiratory diseases. Sharkey et $\mathrm{al}^{20}$ have demonstrated that the initial serum ferritin levels measured among patients with acute respiratory distress syndrome predicts the development of this syndrome and multiple organ failure. Increased concentrations of iron in the lavage fluid of patients with cystic fibrosis have also been observed. ${ }^{21}$ Alternatively, iron deficiency has been shown to be associated with reduced lung function in a large cohort of North American women. ${ }^{22}$ In the context of patients with COPD, a cross-sectional study has reported associations between iron deficiency and reduced exercise tolerance and more frequent exacerbations. ${ }^{23}$ Further studies are needed to clarify the role of iron status in the development of airway obstructive diseases.

Although a major strength of this study is the large number of representative participants and their stratification by lung function, there are several limitations to be accounted for. First, serum ferritin is an acute-phase reactant and may be increased in the presence of inflammation. Given the lack of data on inflammation, infection, or liver disease in our study population, we cannot rule out the potential confounding effect related to the ferritin levels. Similarly, we measured only serum ferritin levels as a marker of iron status, and other iron profiles, such as serum iron levels, transferrin, and total iron-binding capacity, could not be included in the analyses. Finally, due to the nature of cross-sectional cohort studies, causation could not be investigated and a reverse causality cannot be excluded in this study. Therefore, we could not determine whether the positive association between FEV, and $\mathrm{FEV}_{1} / \mathrm{FVC}$ and serum ferritin levels observed in this study indicated enhanced detoxification of iron in individuals with better lung functions, or if adequate body iron storage per se favorably affected spirometric results.

\section{Conclusion}

Serum ferritin levels were increased in former or current smokers and were increased with smoking amount in all 
subgroups of participants categorized according to spirometric results. The result was also evident in the subgroups divided by obstructive severity. While the smoking amount was inversely related to lung function, a higher level of serum ferritin was associated with enhanced spirometric results in a representative sample of the general Korean adult population. Given the findings in this study and the increasing incidence of COPD worldwide, future prospective studies will be needed to clarify the causality between serum ferritin levels and lung function and its role in COPD morbidity.

\section{Author contributions}

CHL, KSC, MSP, YSK, and JHS substantially contributed to conception and design, acquisition of data, or analysis and interpretation of data. CHL, YSK, SKK, and JHS drafted the article or revised it critically for important intellectual content. CHL, EKG, SHL, KSC, JYJ, MSP, YSK, SKK, $\mathrm{JC}$, and JHS made the final approval of the version to be published. CHL, EKG, SHL, KSC, JYJ, MSP, YSK, SKK, JC, and JHS agreed all aspects of the work in ensuring that questions related to the accuracy or integrity of any part of the work are appropriately investigated and resolved. All authors contributed toward data analysis, drafting and critically revising the paper and agree to be accountable for all aspects of the work.

\section{Disclosure}

The authors report no conflicts of interest in this work.

\section{References}

1. Ghio AJ. Disruption of iron homeostasis and lung disease. Biochim Biophys Acta. 2009;1790(7):731-739.

2. Thompson AB, Bohling T, Heires A, Linder J, Rennard SI. Lower respiratory tract iron burden is increased in association with cigarette smoking. J Lab Clin Med. 1991;117(6):493-499.

3. Ghio AJ, Stonehuerner J, Quigley DR. Humic-like substances in cigarette smoke condensate and lung tissue of smokers. Am J Physiol. 1994; 266(4 pt 1):L382-L388.

4. Ghio AJ, Hilborn ED, Stonehuerner JG, et al. Particulate matter in cigarette smoke alters iron homeostasis to produce a biological effect. Am J Respir Crit Care Med. 2008;178(11):1130-1138.

5. Bousquet J, Kiley J, Bateman ED, et al. Prioritised research agenda for prevention and control of chronic respiratory diseases. Eur Resp J. 2010;36(5):995-1001.

International Journal of COPD

\section{Publish your work in this journal}

The International Journal of COPD is an international, peer-reviewed journal of therapeutics and pharmacology focusing on concise rapid reporting of clinical studies and reviews in COPD. Special focus is given to the pathophysiological processes underlying the disease, intervention programs, patient focused education, and self management protocols.
6. Yoo KH, Kim YS, Sheen SS, et al. Prevalence of chronic obstructive pulmonary disease in Korea: the fourth Korean National Health and Nutrition Examination Survey, 2008. Respirology. 2011;16(4):659-665.

7. Taylor JC, Madison R, Kosinska D. Is antioxidant deficiency related to chronic obstructive pulmonary disease? Am Rev Respir Dis. 1986;134(2): 285-289.

8. Kinnula VL. Focus on antioxidant enzymes and antioxidant strategies in smoking related airway diseases. Thorax. 2005;60(8):693-700.

9. Eisner MD, Anthonisen N, Coultas D, et al. An official American Thoracic Society public policy statement: novel risk factors and the global burden of chronic obstructive pulmonary disease. Am J Respir Crit Care Med. 2010;182(5):693-718.

10. Arosio P, Levi S. Ferritin, iron homeostasis, and oxidative damage. Free Radic Biol Med. 2002;33(4):457-463.

11. Miller MR, Hankinson J, Brusasco V, et al. Standardisation of spirometry. Eur Respir J. 2005;26(2):319-338.

12. Vestbo J, Hurd SS, Agusti AG, et al. Global strategy for the diagnosis, management, and prevention of chronic obstructive pulmonary disease: GOLD executive summary. Am J Respir Crit Care Med. 2013;187(4): 347-365.

13. Stohs SJ, Bagchi D. Oxidative mechanisms in the toxicity of metal ions. Free Radic Biol Med. 1995;18(2):321-336.

14. Pryor WA. Cigarette smoke radicals and the role of free radicals in chemical carcinogenicity. Environ Health Perspect. 1997;105(suppl 4): 875-882.

15. Moreno JJ, Foroozesh M, Church DF, Pryor WA. Release of iron from ferritin by aqueous extracts of cigarette smoke. Chem Res Toxicol. 1992;5(1):116-123.

16. Lapenna D, de Gioia S, Mezzetti A, et al. Cigarette smoke, ferritin, and lipid peroxidation. Am J Respir Crit Care Med. 1995;151(2 pt 1): 431-435.

17. Wesselius LJ, Flowers CH, Skikne BS. Alveolar macrophage content of isoferritins and transferrin. Comparison of nonsmokers and smokers with and without chronic airflow obstruction. Am Rev Respir Dis. 1992; 145(2 pt 1):311-316.

18. Turi JL, Yang F, Garrick MD, Piantadosi CA, Ghio AJ. The iron cycle and oxidative stress in the lung. Free Radic Biol Med. 2004;36(7):850-857.

19. Touitou Y, Proust J, Carayon A, et al. Plasma ferritin in old age. Influence of biological and pathological factors in a large elderly population. Clin Chim Acta. 1985;149(1):37-45.

20. Sharkey RA, Donnelly SC, Connelly KG, Robertson CE, Haslett C, Repine JE. Initial serum ferritin levels in patients with multiple trauma and the subsequent development of acute respiratory distress syndrome. Am J Respir Crit Care Med. 1999;159(5 pt 1):1506-1509.

21. Reid DW, Lam QT, Schneider H, Walters EH. Airway iron and iron-regulatory cytokines in cystic fibrosis. Eur Respir J. 2004;24(2):286-291.

22. Brigham EP, McCormack MC, Takemoto CM, Matsui EC. Iron status is associated with asthma and lung function in US women. PLoS One. 2015;10(2):e0117545.

23. Nickol AH, Frise MC, Cheng HY, et al. A cross-sectional study of the prevalence and associations of iron deficiency in a cohort of patients with chronic obstructive pulmonary disease. BMJ Open. 2015;5(7):e007911.

This journal is indexed on PubMed Central, MedLine and CAS. The manuscript management system is completely online and includes a very quick and fair peer-review system, which is all easy to use. Visit http://www.dovepress.com/testimonials.php to read real quotes from published authors. 